\title{
Post-Modern Epidemiology: Back to the Populations
}

\author{
Arnaud Chiolero 1,2,3 (D) \\ 1 Population Health Laboratory (\#PopHealthLab), University of Fribourg, Route des Arsenaux 41, \\ 1700 Fribourg, Switzerland; arnaud.chiolero@unifr.ch \\ 2 Institute of Primary Health Care (BIHAM), University of Bern, 3012 Bern, Switzerland \\ 3 Department of Epidemiology, Biostatistics, and Occupational Health, McGill University, \\ Montreal, QC H3A 1A2, Canada
}

Received: 14 August 2020; Accepted: 18 August 2020; Published: 19 August 2020

check for updates

The creation of new journal about epidemiology is a good opportunity to think about the state of the field and to make proposals for its development. I argue here that it is time for post-modern epidemiology.

Epidemiology has moved from "traditional" to what is called "modern epidemiology" with the development of risk factor epidemiology [1] (Table 1). The risk factor approach was key, notably, to identify major and modifiable causes of cardiovascular diseases and to help prevent them. It was also aligned with the motivation for epidemiologists to engage in science, explanation being at the heart of modern epidemiology. This approach failed, however, to address the social, economic, and environmental determinants of health. Further, it moved the field of epidemiology from a population perspective to an individual one [1].

Other trends with a major impact on epidemiology are the development of data-science and the growing access to big and highly heterogenous health-related data [2]. These data are changing observational research as well as the field of public health surveillance and population health monitoring through a widening scope of applications and new methods. Despite an unprecedented access to data, the Covid-19 pandemic has, however, revealed the failure of most public health surveillance systems worldwide, making their reinventions necessary.

Further, while there is a renewed interest in social and environmental epidemiology, notably through the development of life course epidemiology [3], the defiance toward epidemiology has never been so strong [4] and this is due to the major failures of some observational studies, the enduring confusion between association and causality, the large number of studies reporting false-positive results [5], and the production of low value research without public health relevance [6,7].

Within this context, I would like to make three proposals for the development of post-modern epidemiology.

Firstly, we should re-enchant public health surveillance and population health monitoring and put description at the forefront of epidemiology. Opportunities through the developments of data science are huge; new data and new methods for visualization or mining, as well as machine learning and artificial intelligence, are transforming the field of epidemiology and surveillance [2]. These new and "big" data, however, do not speak by themselves more than "small" data, and making sound epidemiological research and providing information useful for the decision in public health requires, more than ever, a training that goes far beyond the mastery of data management and analyses [8]. 
Table 1. Features of traditional, modern, and post-modern epidemiology. Adapted from Pearce 1996 [1].

\begin{tabular}{lccc}
\hline & Traditional Epidemiology & Modern Epidemiology & Post-Modern Epidemiology \\
\hline Motivation & Public health & Science & Population health \\
Level of study & Population & Individual & Multiple, social, environmental; \\
& & across the life course & Public health surveillance and \\
Paradigms & Demography and social & Biomedicine, clinical trial and & population health monitoring; \\
data science and causality & biostatistics & Consequentialist \\
Epistemological approach & science & Positivist & Population and individual \\
Level of intervention & Realist & Individual & \\
\hline
\end{tabular}


Secondly, we should apply new developments in causal inference methodology to overcome some failures of risk factor epidemiology $[4,8]$. To get causal inference from observational data right, it is wise to distinguish three classes of epidemiological tasks: (1) description, (2) prediction, and (3) causal inference [8]. Furthermore, applying a counterfactual and interventionist approach will help prevent inferential mistakes due to the confusion between a statistical association and a cause-a plague in the field of social, environmental, and life course epidemiology. This approach also matches public health needs by explicitly linking causes with interventions having an effect on the health of populations [4].

Thirdly, we should aim, systematically, for consequential epidemiology [7] and put intervention at the forefront of epidemiology. The concern of post-modern epidemiology should be to improve the health of populations more than tackling their determinants. We should also take distance from individual risk factor epidemiology and rather aim to solve issues at a population level, through interventions designed by data-informed and evidence-based population health science $[9,10]$. This will be necessary if we want to address (and not only understand) the social and environmental determinants of health [10].

In brief, for the post-modern era, I propose epidemiology to go back to the populations [11,12], and to give less weight to explanations and more to descriptions and interventions.

Conflicts of Interest: The authors declare no conflict of interest.

\section{References}

1. Pearce, N. Traditional epidemiology, modern epidemiology, and public health. Am. J. Public Health 1996, 86, 678-683. [CrossRef] [PubMed]

2. Chiolero, A.; Buckeridge, D. Glossary for public health surveillance in the age of data science. J. Epidemiol. Commun. Health 2020, 74, 612-616. [CrossRef] [PubMed]

3. Kuh, D.; Ben-Shlomo, Y.; Lynch, J.; Hallqvist, J.; Power, C. Life course epidemiology. J. Epidemiol. Commun. Health 2003, 57, 778-783. [CrossRef] [PubMed]

4. Chiolero, A. Counterfactual and interventionist approach to cure risk factor epidemiology. Int. J. Epidemiol. 2016, 45, 2202-2203. [CrossRef] [PubMed]

5. Ioannidis, J.P. Why most published research findings are false. PLoS Med. 2005, 2, e124. [CrossRef] [PubMed]

6. Ioannidis, J.P.; Greenland, S.; Hlatky, M.A.; Khoury, M.J.; Macleod, M.R.; Moher, D.; Schulz, K.F.; Tibshirani, R. Increasing value and reducing waste in research design, conduct, and analysis. Lancet 2014, 383, 166-175. [CrossRef]

7. Galea, S. An argument for a consequentialist epidemiology. Am. J. Epidemiol. 2013, 178, 1185-1191. [CrossRef] [PubMed]

8. Hernan, M.A. Data science is science's second chance to get causal inference right: A classification of data science tasks. Chance 2019, 32, 42-49. [CrossRef]

9. Gray, M.; Ricciardi, W. From public health to population medicine: The contribution of public health to health care services. Eur. J. Public Health 2010, 20, 366-367. [CrossRef] [PubMed]

10. Galea, S.; Keyes, K.M. Epidemiology at the heart of population health science. Am. J. Epidemiol. 2019, 188, 883-885. [CrossRef] [PubMed]

11. Rose, G. Sick individuals and sick populations. Int. J. Epidemiol. 1985, 14, 32-38. [CrossRef] [PubMed]

12. Rose, G. Strategy of Preventive Medicine; Oxford University Press: Oxford, UK, 1992; Re-edited in 2008.

(C) 2020 by the author. Licensee MDPI, Basel, Switzerland. This article is an open access article distributed under the terms and conditions of the Creative Commons Attribution (CC BY) license (http://creativecommons.org/licenses/by/4.0/). 